\title{
A arte de saborear maçãs ácidas: a recepção de fenômenos incomuns pelos pioneiros da Psicanálise
}

\author{
Karin Hellen Kepler Wondracek
}

\section{RESUMO}

Uma incursão aos primórdios da psicanálise com o objetivo de estabelecer recortes históricos a respeito da recepção de fenômenos incomuns como telepatia, mediunidade e, experiências de quase-morte em alguns pioneiros da psicanálise. Entre estes, destaca-se a atitude cuidadosa e reticente de Freud a respeito da telepatia, a curiosidade de Ferenczi para com a premonição e mediunidade, e os estudos de Oskar Pfister sobre experiências de quasemorte. Embora afirmados como campos separados, mostra-se que não deixaram de influenciar as teorizações, especialmente da comunicação inconsciente e da empatia. Destaca-se ainda a afirmação pioneira da interdisciplina para compreensão mais profunda desses fenômenos, antecipatória do atual quadro epistemológico para tais estudos.

Palavras-chave: Psicanálise; telepatia; EQM; comunicação inconsciente; transferência.

\section{ABSTRACT}

An incursion to the beginnings of psychoanalysis with the objective to establish historical cuts in respect to the reception of uncommon phenomena such as telepathy, mediumship, and near-death experiences of some pioneers of psychoanalysis. Among these, the careful and reluctant attitude of Freud in respect to telepathy, the curiosity of Ferenczi towards premonitions and mediumship, and the studies of Oscar Pfister about near-death experiences stand out. Although affirmed in separate fields, it is shown that they have not ceased to influence theorizations, especially unconscious communication and empathy. Also highlighted is that the pioneer affirmation of the interdiscipline for deeper understanding of these phenomena, anticipatory of the epistemological framework for such studies.

Keywords: Psychoanalysis; telepathy; NDE; unconscious communication; transference.

"Pensar nessa maçã ácida me faz tremer mas não há meio de evitar ter que mordê-la"

(Freud a Eitingon)

0 estudo dos fenômenos incomuns, significativamente expresso na linguagem da fase oral, é comparado por Sigmund Freud à ingestão de um fruto ácido, mas obrigatório. A obrigatoriedade, segundo Cristine Alberti (2011), vem de sua coerência e rigor perante fenômenos que não podem ser ignorados. Mas a maçã será mordida aos poucos, com método, paixão e parcimônia. Em outras palavras, os fenômenos ocultos são investigados primeiramente para sua desocultação. Inspirado em seu mestre Charcot de que "teoria é bom, mas não impede que os fatos existam" (Freud, 1925, p. 24), Freud mostra abertura e receio em relação aos fenômenos. Em outras palavras, sinal de ambivalência (Vieira, 2017).

Vieira comenta que dos três trabalhos de Freud, o primeiro nunca foi lançado em vida, por temor dos pares de Freud de aproximar a psicanálise do ambiente místico que ronda esses fenômenos. Mas Freud não descarta o estudo desses fenômenos, pois mesmo que tenha aproximado a psicanálise do paradigma científico mais "duro", também não se furtou a incluir em suas pesquisas fenômenos relegados pela ciência oficial. (Vieira, 2017, p. 59) Para Freud,

\section{Sobre a Autora}

K. H. K. W. orcid.org/0000-0002-5713-5016

Faculdades EST - São Leopoldo

karinkw@gmail.com

\section{Direitos Autorais}

Este é um artigo de acesso aberto e pode ser reproduzido livremente, distribuído,

transmitido ou modificado, por qualquer pessoa desde que usado sem fins comerciais. trabalho é disponibilizado sob a licença Creative Commons CCBY-NC

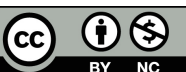




\section{H. INTERACÃO EM LF PSICOLOGIA}

os membros de seu "comitê secreto" eram incapazes de suspender suas certezas preconcebidas; dizia Freud que seus pares eram "fundamentalmente mecanicistas e materialistas incorrigíveis" (Freud, 1921 [1941] como citado em Vieira, 2017, p. 27).

Uma dica de Alberti (2011) para seguir nesse campo de sabores ácidos: aproximar-se da relação 'acessória' de Freud com os fenômenos incomuns em atitude analítica, que não negligencia elementos periféricos nem contraditórios, antes vê neles pistas de formações do inconsciente.

É necessário manter a atenção flutuante, para que a contribuição de Freud possa se tornar efetiva também nesse campo. "Assim como Freud avançou no século, a partir de seus próprios sonhos e atos falhos, ele sempre testemunhou sua sensibilidade pessoal aos fenômenos ocultos (premonições, profecias, telepatia), a começar por suas próprias superstições." (Alberti, 2011, s.p.) 0 autor remete à biografia de Ernest Jones, na qual atesta o interesse de Freud por saborear relatos estranhos e experiências inquietantes sobre estes campos.

0 primeiro relato telepático está numa carta à sua noiva Marta: um mês após o noivado, Freud rompe acidentalmente o anel. Então escreve à noiva perguntando se nesse dia, às 11 horas, ela o amara menos (Alberti, 2011). No Psicopatologia da vida cotidiana (1901) expressa que tais crenças são oriundas de pensamentos, medos, desejos reprimidos, por vezes de morte da pessoa amada.

Se esse era o discurso oficial, na esfera privada Freud faz experimentos em telepatia com sua filha Anna. Para o constrangimento de alguns, Freud ainda dizia que Anna possuía clara "sensibilidade telepática" (Gay, 1989, p. 404). Estes experimentos permanecem no âmbito privado, pois Freud sente $o$ risco de aproximar a psicanálise perigosamente do ocultismo, e assim tornar ainda mais difícil sua aceitação como disciplina científica.

Sandor Ferenczi e Carl Gustav Jung foram os interlocutores para esses temas. Durante a viagem aos Estados Unidos, em 1909, o tema é discutido em profundidade. Seis meses depois do retorno, Freud "autoriza" Ferenczi a investigar a médium Frau Seidler, conhecida por suas habilidades de adivinhar pensamentos. (Vieira, 2017, p. 48). Após a cisão com Jung, Ferenczi se torna o privilegiado investigador desses temas, como veremos adiante.

Se considerações da "política exterior" obrigaram Freud a reduzir toda publicidade sobre essas questões e a adiar a publicação de seus textos, é durante o verão de 1921, após recusar três contribuições a periódicos dedicados ao ocultismo, que ele se decide a fazer uma comunicação para seu grupo mais íntimo.

O primeiro dos textos, Psicanálise e Telepatia (1921/1941) é escrito para ser lido aos membros do Comitê - Abraham, Eitington, Ferenczi, Jones, Rank e Sachs - na cidade de Gastein. Este texto nunca foi publicado'. No planejamento de sua fala, Freud quer ilustrar com três casos, mas esquece as anotações de um deles. E interpreta-o como resistência. Os outros dois casos são explicados mais como realização de desejo, como comunicação inconsciente de algo recalcado. Conforme Bernardino, o maior ponto de interesse de Freud nesse texto reside na investigação da transmissão de pensamentos. Quer retirá-la do campo do ocultismo

"para tentar analisá-la à luz de suas descobertas sobre o inconsciente, o desejo e a transferência. Retenhamos mais um ponto, pois: trata-se de um desejo extremamente poderoso, inconsciente, que não se expressa pela via da palavra falada, mas encontra expressão em outra pessoa, cuja consciência está a serviço desta recepção." (Bernardino, 2005, p. 98)

No ano seguinte, 1922, em outro texto, Freud discute a relação entre Sonhos e Telepatia. Aparece na análise de uma carta de um pai que teve um sonho premonitório com a filha, a seguinte constatação: "existia um vínculo íntimo de sentimento entre o pai e a filha" (Freud, 1922, p. 248). Em seguida, embora enunciando que "a telepatia nada tem a ver com a natureza dos sonhos" (Freud, 1922, p.250), faz uma diferenciação entre sonho e estado de sono. Mostra ainda outra diferença: enquanto o sonho é produto da vida mental, a concepção de "sonho telepático" pressupõe, segundo ele, "uma percepção de algo externo perante o qual a mente permanece passiva e receptiva" (Freud, 1922, p. 251). Conclui o artigo afirmando: "o sono cria condições favoráveis à telepatia (...) as leis da vida mental inconsciente se aplicam à telepatia" (Freud, 1922, p. 264).

Em carta a Jones em 1926, em tom de confissão, fala de seu "preconceito favorável à telepatia" e tenta mantê-lo longe do desenvolvimento da psicanálise. É seu assunto particular, sua 'Queda no Pecado', "assim como meu judaísmo, minha paixão por fumar e outras coisas, e (...) não essencial para a psicanálise" (Gay, 1989, p. 406).

Em sua justificação a Jones afırma que é a revisão de sua obra Interpretação dos sonhos que o conduz daí em diante a reconsiderar sua posição: "Uma vez mais me era necessário pensar em repetir, em uma escala reduzida, a grande

\footnotetext{
1 Segundo Viera (2017, p. 32) a ambivalência no caso de publicação se deve a embaraços na revelação da familiaridade de Freud com os fenômenos ocultos e a tensões editoriais da época.
} 


\section{-4: INTERACÃO EM F PSICOLOGIA}

experiência de minha vida: a saber, a proclamação de uma convicção sem levar em conta qualquer eco vindo do mundo exterior" (Gay, 1989, p. 406). São os fenômenos da transmissão de pensamento que constituem, aos olhos de Freud, o "núcleo de verdade" do ocultismo. Admite que a ideia não seja agradável em seu meio, mas por coerência precisa expressá-la: "Isso não me agrada a mim também, mas há aí dentro alguma verdade." (Freud como citado em Alberti, 2011, s.p.)

Enquanto isso, Ferenczi funciona como catalisador do assunto, mais do que autor independente. Na pesquisa de mestrado sobre Freud e Ferenczi, Vieira (2017) mostra como essa investigação conduzida por Ferenczi e supervisionada por Freud foi significativa para a compreensão do papel da intersubjetividade na psicanálise, especialmente da transferência. A pesquisa de ambos atualiza desse modo o conceito-chave incluindo uma dimensão não verbal na transferência e põe a manifesto nuances que já estavam embutidas desde o início. A telepatia é aproximada da introjeção, junto à empatia e à intuição. Freud chamou os fenômenos telepáticos de "transferência de pensamentos": "Durante uma transferência de pensamentos, um dos participantes introjeta as palavras-estímulos através do inconsciente enquanto o outro sujeito opera do mesmo modo com as projeções". (Freud como citado em Vieira, 2017, p. 22). A telepatia se torna um meio de captação de afetos e pensamentos que utiliza um meio arcaico não verbal, caracterizado pela ausência de controle consciente. (Freud como citado em Vieira, 2017, p. 26)

Além das observações derivadas das sessões com seus próprios pacientes e da pesquisa realizada com Frau Seidler, Ferenczi também investiga Frau Jelinek, uma vidente de Budapeste. Em caráter privado, Freud reage com entusiasmo e dá trânsito livre às suas pesquisas. Mas coloca obstáculos para que apresente os resultados no Congresso de Psicanálise de Bad Homburg em 1925, bem como lhe pede para esperar para publicá-las.

"Transferência e contratransferência são fenômenos produzidos a partir dos processos constitutivos de introjeção e projeção; neles, os conteúdos interiores e exteriores do psiquismo poderiam ser transmitidos e confundidos. Tal perspectiva estaria sustentada na sensibilidade particular que é constituída nas situações transferenciais." (Ferenczi, 1928/2011 como citado em Vieira, 2017, p. 46).

Os pilares para tais afırmações estão fundados nas pesquisas de Ferenczi sobre ocultismo, que the possibilitaram construir a hipótese mais radical da transmissão de ideias. Essa hipótese, por sua vez, abre o campo para um estudo mais aprofundado da contratransferência, como importantíssimo instrumento da clínica psicanalítica. (Vieira, 2017)

Doze anos mais tarde Freud retoma o tema na Conferência XXX Sonhos e ocultismo (Freud 1933). Na introdução, uma modificação na atitude de Freud a respeito da relação entre psicanálise e telepatia: a aceitação desses fenômenos já não ameaça a Weltansschauung científica e a psicanálise. "Nós, analistas, temos motivos especiais para sermos cautelosos no uso das considerações intelectuais para rejeitar hipóteses novas, e devemos admitir que elas não nos isentam de sentimentos de antipatia, dúvida e incerteza". (Freud, 1933/1977, p. 47)

Em vários momentos dessa conferência são estabelecidas relações entre a pesquisa psicanalítica e a pesquisa dos fenômenos incomuns, com aposta na pesquisa futura: A própria psicanálise foi capaz de mostrar que algo psíquico, como o inconsciente, se converte em fenômeno físico, e no futuro poderá ser essa mesma lógica a provar a existência de fenômenos como telepatia. Com uma ressalva: não será a psicanálise que fará esse trabalho, pois esse não é seu campo. "A única coisa adicional que poderia fazer, seria relatar-lhes observações que pelo menos têm tanta relação com a psicanálise, por terem sido feitas durante tratamento psicanalítico e, até mesmo, talvez, se tornaram possíveis por influências desta." (Freud, 1933/1977, p. 63)

Neste texto Freud vence sua resistência e traz o terceiro caso, aquele que não conseguira apresentar em 1921. O conteúdo diz respeito à relação com o paciente conhecido como Herr P.: há dois momentos "telepáticos" durante as sessões. No primeiro, o paciente associa palavras que se assemelham ao sobrenome de um ilustre professor londrino que visitara Freud no horário anterior ao paciente (Forsith Vorsicht). No segundo fragmento, o paciente traz associações com o nome de um amigo de Freud, que morava no mesmo prédio do paciente, ditas após a visita de Freud ao amigo, da qual o paciente não tivera conhecimento.

Dois eventos diferentes, nos quais aparecem indícios de conteúdos que não poderiam ser do conhecimento consciente de Herr P. E declarando-se um velho cético que desconfia do seu ceticismo (Freud, 1933/1977, p. 70), mas que também não se tornou um "velho parvo, piedoso e ingênuo" (Freud, 1933/1977,1933, p. 67), afirma que pode haver uma comunicação entre duas mentes, e o funcionamento do telefone dá a analogia: há um processo mental no emissor que é convertido em processo físico ainda desconhecido, que novamente é convertido em processo mental no pensamento do receptor (Freud, 1933/1977, p. 72). Freud enuncia a hipótese de que possa se tratar "de um método original, arcaico, de comunicação entre indivíduos" (Freud, 1933/1977, p. 73), provavelmente 


\section{-4: INTERACÃO EM F PSICOLOGIA}

existente antes da comunicação oral e que pode ser ativado em determinadas condições, como "em multidões de pessoas apaixonadamente excitadas" (Freud, 1933/1977, p. 73). E acrescenta em tom conciliatório: "Tudo isso ainda é incerto e pleno de enigmas não solucionados; não há, porém razão para temê-lo". (Freud, 1933/1977, p. 73).

Freud concilia nesse texto sua abertura e seu rigor; duvidando do seu ceticismo, mas também não se entregando à ingenuidade, abre-se para outros campos. Ao mesmo tempo, mantém as fronteiras do seu próprio saber em abertura, que hoje nomearíamos de interdisciplinar.

\section{PFISTER E SUAS DIGRESSÕES SOBRE FENÔMENOS INCOMUNS}

A correspondência Freud-Pfister (1963/1998), reveladora dos bastidores das ideias a respeito dos fenômenos religiosos, também se torna importante fonte a respeito das pesquisas sobre fenômenos incomuns. Os dois amigos trocam impressões sobre seus textos a respeito desse tema, numa atitude de respeito e tolerância para com o diferente, que ainda fertiliza os diálogos atuais (Wondracek, 2005).

Os trabalhos de Pfister procuram mostrar a distância entre religiosidade alicerçada na razão e essas manifestações incomuns, que considera religiosidade distorcida por pulsões reprimidas. Mas tal como Freud em seus anos tardios, Pfister também parece mostrar mais abertura em 1931, no seu texto Schockdenken und Schockphantasien bei höchster Todesgefahr [Pensamentos e fantasias em estado de choque frente a perigos de morte] nesse caso sobre experiências de quase-morte (EQM). Para isto, toma as pesquisas empíricas do geólogo Albert Heim, a respeito das mesmas.

Heim conclui que $95 \%$ das pessoas apresentam elementos comuns nas fantasias durante a queda, como ausência de medo, dor ou pânico, lucidez quanto a ações a tomar para sobreviver, retrospectiva de toda vida, privilegiando o belo e amoroso, audição alucinatória de música e visão de um céu azulado com nuvens róseas.

Dentro da sua concepção progressista, Pfister (1931) interpreta estas fantasias não como escapistas, mas como protetoras da pulsão vital. Utiliza-se do conceito de "tela protetora", desenvolvido por Freud em 1921 no Além do princípio do prazer, para explicá-las como proteção construída pelo ego frente ao traumático. A tela protetora durante a queda é relacionada com a função protetora do sonho: assim como este último protege o sono e quer impedir o despertar, as fantasias em estado de choque preservam a consciência da pessoa e impedem o seu desmaio. As fantasias de choque são o "equivalente negativo do sonho".
(Pfister, 1931, p.423) "O inconsciente assume o choque do consciente e o transforma, inteiramente em si mesmo, em complexo cheio de sentimentos consoladores". (Pfister, 1931, p. 414)

Fiel ao contexto psicanalítico do texto, Pfister expressa que não introduzirá ideias de conteúdo religioso. Com uma ressalva, pois acredita que os fenômenos observados apenas terão explicação consistente com a inclusão dessas dimensões. Delicadamente pergunta no texto se seria ousado pensar que no momento da queda e ameaça de morte surge em cena um "instância materna" organizadora, presente no princípio e no final da vida:

...aquela instância criativa, organizadora, seja ela chamada de entelechia, vontade de individuação ou de outra forma, aquela força edificadora que criou, muito antes do surgimento da consciência, as condições para a existência da nossa instância anímica, [e que neste momento] assumisse a direção, de modo que essa instância materna, que governava sobre os inícios da nossa existência individual exerceria seu último serviço de amor também na porta de saída escura, depois de terem fracassadas todas as outras forças de ajuda? (Pfister, 1931, p. 428)

E será que as representações prazerosas daquele que está caindo não se aproximam bem mais da real matéria do que as angústias (...) daquele que permanece completamente consciente? Não posso me aprofundar nestas reflexões que têm como contrapartida o conteúdo real das pretensas ilusões puras e o conteúdo ilusório do suposto pensamento puro. (Pfister, 1931, p. 424)

\section{CONSIDERAÇÕES FINAIS}

O questionamento de Pfister (1931) leva-nos à afirmação de Freud (1922), de que telepatia não será estudada pela psicanálise, mas por outros saberes, aos quais a psicanálise pode fornecer dados preciosos a partir da clínica. Também Pfister (1931) refere que a experiência de quase-morte somente será compreendida se outras dimensões forem incluídas. Foge ao âmbito deste texto fazer a contextualização desse desejo, pois aqui o objetivo foi levantar aspectos históricos sobre a relação da psicanálise com fenômenos incomuns e apontar sua influência em alguns conceitos psicanalíticos.

Voltamos aos pioneiros: Freud, Ferenczi e Pfister... e ainda poderíamos acrescentar outros como Helen Deutsch e Hermine Hugh-Helmuth. As maçãs ácidas da telepatia e dos demais fenômenos incomuns deixam aos poucos de ser fruto do "pecado original" do querer saber mais, já não têm o poder de expulsar a psicanálise do jardim da academia. 


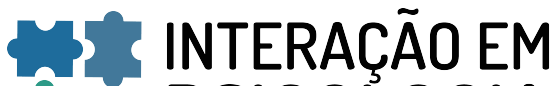 ET PSICOLOGIA}

Antes, reconhecem-se os nexos e as ligações: desde seu mestre Charcot, Freud sabe que a teoria nem sempre abrange os fatos. Freud, como criador da psicanálise, foi decifrador de fatos nada comuns nos sonhos, atos falhos e sintomas, e paulatinamente abriu sua mente para os fenômenos incomuns, sem perder a especificidade da sua área. A crítica aos discípulos demasiadamente mecanicistas continua válida, infelizmente!

Muito ainda está por ser descoberto e sistematizado, e a clínica agradecerá a abertura da escuta sem esquema psicopatológico prévio. A clínica já é devedora dessa investigação, pois como expressa Vieira (2017), os estudos sobre telepatia lançaram as bases para compreender a empatia e a comunicação inconsciente da transferência.

Em relação aos fenômenos incomuns religiosos, aprendemos com Freud, Ferenczi e Pfister que é preciso trabalhar em si as resistências aos fatos, para não querer enquadrá-los no conhecido. Apenas para indicar uma possibilidade apontada por Felícia Knobloch (1998) e também por Wondracek (2010): considerar que a segunda tópica da psicanálise favorece mais a compreensão de fenômenos incomuns, visto que a representabilidade deixa de ser o modelo de compreensão do funcionamento do psiquismo. Com o id, a pulsão é introduzida no aparelho anímico e desta forma outras modalidades de força pulsional que não a representação, ganham lugar.

Talvez estas sejam as forças que se comunicam de outra forma que a simbolização linguageira, e aos poucos saem do desconhecimento a que foram relegadas pelas próximas gerações de psicanalistas. Aos poucos, estamos redescobrindo e criando modos de saborear maçãs ácidas...

\section{DECLARAÇÃO DE FINANCIAMENTO}

A pesquisa relatada foi financiada integralmente pela autora.

\section{DECLARAÇÃO DE CONFLITOS DE INTERESSE}

A autora declara que não há conflitos de interesse no manuscrito submetido.

\section{REFERÊNCIAS}

Alberti, C. (2011, setembro). Freud e o oculto. Latusa Digital, 8(46), páginas. Retirado de http://www.latusa.com.br/ pdf_latusa_digital_46_a1.pdf
Bernardino, L. M. F. (2005). The role of the research in the psychoanalytical clinic with babies and their parents. In: Colóquio Franco-Brasileiro sobre Clínica com Bebês, 1., Paris. Retirado de Disponível em: <http:// www.proceedings.scielo.br/scielo.php? script=sci_arttext\&pid=MSC0000000072005000100002\&l $\mathrm{ng}=\mathrm{en} \& \mathrm{nrm}=\mathrm{abn}$. Acess on: 18 Nov. 2017.

Ferenczi, S. (1928/2011). A elasticidade na técnica analítica. Obras completas, Vol IV. São Paulo: Martins Fontes.

Freud, E.; Meng, H. (1963/1998). Cartas entre Freud e Pfister. Viçosa: Ultimato.

Freud, S. (1921/1977). Além do princípio do prazer. Edição Standard Brasileira das Obras Psicológicas Completas de Sigmund Freud. Rio de Janeiro: Imago.

Freud, S. (1921/1946/1977). Psicanálise e telepatia. Edição Standard Brasileira das Obras Psicológicas Completas de Sigmund Freud. Rio de Janeiro: Imago.

Freud, S. (1922/1977). Sonhos e telepatia. In: Edição Standard Brasileira das Obras Psicológicas Completas de Sigmund Freud. Rio de Janeiro: Imago.

Freud, S. (1933/1977). Sonhos e ocultismo. In: Edição Standard Brasileira das Obras Psicológicas Completas de Sigmund Freud. Vol XXII. Rio de Janeiro: Imago.

Gay, P. (1989) Freud: uma vida para o nosso tempo. São Paulo: Companhia das Letras

Knobloch, F. (1998). O tempo do traumático. São Paulo: EDUC.

Pfister, O. (1931). Schockdenken und Schockphantasien bei höchster Todesgefahr [Pensamentos e fantasias em estado de choque frente a perigos de morte]. Internationale Zeitschrift für Psychoanalyse, 16, 430-435.

Vieira, B. D. A. (2017). A empatia em Freud e em Ferenczi: em busca de uma ferramenta para a clínica psicanalítica. Dissertação de mestrado, Universidade de São Paulo.

Wondracek, K. H. K. (2005). O amor e seus destinos: a contribuição de Oskar Pfister para o diálogo entre teologia e psicanálise. São Leopoldo: Sinodal.

Wondracek, K. H. K. (2010). Ser nascido na vida: a contribuição da fenomenologia da vida de Michel Henry para a clínica.Tese de doutorado, Escola Superior de Teologia, São Leopoldo, Rio Grande do Sul, Brasil. Disponível em http://dspace.est.edu.br:8080/jspui/handle/ BR-SIFE/158

Recebido em 19.02.2019 Primeira Decisão Editorial em 25.02.2019 Aceito em 26.04.2019 